\title{
Principios de Derecho Administrativo Sancionador, de Natalia Veloso Giribaldi (Coordinadora), Universidad de Montevideo, Montevideo, 2021
}

\section{FEDERICO FISCHER CASTELLS}

Es un honor comentar la publicación "Principios de Derecho Administrativo Sancionador", coordinada por la Prof. Dra. Natalia Veloso Giribaldi, que presenta un estudio sistematizado de los diversos principios generales que son aplicables al derecho administrativo sancionador.

La obra comentada tiene su génesis en la primera edición del curso Derecho Administrativo Sancionador dictado por la Prof. Dra. Veloso Giribaldi en el año 2020 en el marco de la Maestría de Derecho Administrativo Económico de la Universidad de Montevideo (para la cual el curso de Derecho Administrativo Sancionador constituye una muy valiosa y oportuna adición).

La publicación recoge una selección de los trabajos de investigación final que realizaran los maestrandos que participaron del curso mencionado sobre los principios de derecho administrativo sancionador, así como valiosos aportes del Prof. Dr. Carlos Delpiazzo y diversos trabajos de la Prof. Dra. Veloso Giribaldi en la materia.

No caben dudas que esta publicación constituye un aporte fundamental a la doctrina administrativista y al estudio del derecho administrativo sancionador, de gran trascendencia y aplicación tanto teórica como práctica.

En primer lugar, en virtud de la actualidad de la temática abordada.

Es innegable que la potestad sancionatoria estatal ha experimentado un crecimiento en el Estado moderno y que hoy constituye un instrumento de vital trascendencia para el cumplimiento de sus fines, especialmente en su rol de regulador de diversas actividades de interés público.

Así, el avance de la presencia estatal en un número creciente de manifestaciones de la actividad individual determina también un correlativo avance de la potestad sancionatoria, que se despliega con cada vez mayor intensidad sobre los individuos. El elenco de infracciones y sanciones administrativas consagradas por el ordenamiento jurídico es amplísimo y diverso, y - en cuanto a las sanciones - abarca desde un simple apercibimiento u observación a multas con topes millonarios, así como sanciones que imponen graves limitaciones a derechos individuales, como ser clausura de establecimientos e inhabilitaciones, entre otras.

Todo lo cual lleva a que los aportes dogmáticos que profundicen sobre la disciplina del derecho administrativo sancionatorio resulten de alta utilidad e interés.

En segundo lugar, en virtud del objeto de estudio elegido dentro del derecho administrativo sancionador: sus principios generales.

Si bien el estudio de los principios generales que rigen una determinada rama del derecho siempre constituye un valioso aporte, su estudio tiene una especial relevancia en el ámbito del derecho administrativo sancionador. 
Es importante tener en cuenta que la teoría del derecho administrativo sancionador, en tanto rama autónoma del derecho administrativo y con principios propios, se encuentra aún en plena construcción y desarrollo, y sus contornos no han sido plenamente delineados.

Asimismo, dada la naturaleza no codificada de esta rama del derecho (y del derecho administrativo en general) y el hecho de que la potestad sancionatoria abarque materias muy diversas, las normas de derecho positivo en materia sancionatoria no están unificadas y en muchos casos tienen diferente regulación según la Administración o la temática de la que se trate. Lo que crea dificultades para elaborar un marco teórico unificado.

En este contexto, los principios generales del derecho administrativo sancionador, en tanto mandatos de optimización, al decir de ALEXY, cumplen un rol fundamental para la aplicación, integración e interpretación del derecho administrativo sancionador.

Finalmente, en tercer lugar, dado que abarca un estudio pormenorizado y abarcativo de los principios generales que rigen el derecho administrativo sancionador.

La publicación es de especial importancia ya que estudia y analiza todos los principios fundamentales del derecho administrativo sancionador.

Se trata de un valioso aporte a la doctrina administrativista en la materia, ya que si bien la doctrina nacional ha abordado el estudio de esta temática, no existía una obra de la naturaleza de esta publicación, que abordara en forma sistemática y tan completa en una misma publicación todos los principios generales del derecho administrativo sancionador.

Por lo que estamos seguros de que esta publicación será fuente de consulta para futuros aportes doctrinarios en esta materia, así como para la aplicación práctica de la normativa de derecho administrativo sancionatorio.

A lo largo de ocho capítulos, la publicación "Principios de Derecho Administrativo Sancionador" analiza, en profundidad y desde varias ópticas, los principios generales del derecho administrativo sancionador y diversas temáticas de gran actualidad relacionadas con los mismos.

En el Capítulo I, se aborda el principio de limitación, estudiándose por el Prof. Dr. Carlos Delpiazzo los límites que la Constitución y los principios generales del derecho imponen al ejercicio de la potestad administrativa sancionatoria al imponer.

En el Capítulo II, se aborda el estudio del principio de tipicidad. La Prof. Dra. Veloso Giribaldi analiza con carácter general la aplicación del principio general en el derecho sancionatorio. Asimismo, la Dra. Yully Lacerda Neves, realiza un estudio y sistematización de la jurisprudencia reciente del Tribunal de lo Contencioso Administrativo en materia de la aplicación del principio de legalidad, tipicidad y la reserva de ley, en materia sancionatoria.

En el Capítulo III, se aborda el principio de culpabilidad. La Dra. Josefina de la Fuente estudia a la culpabilidad como elemento de la infracción administrativa y su aplicación en la práctica del derecho administrativo sancionador. Por su parte, la Dra. Tatiana Rodriguez Percíncula analiza la jurisprudencia del Tribunal de lo Contencioso Administrativo, enfocándose en la admisibilidad de las infracciones objetivas en el derecho administrativo sancionador. Finalmente, la Dra. Andrea Piccardo Lapi, aborda la temática del principio de 
culpabilidad desde la óptica de la prueba indiciaria y su aplicación a la luz del principio de presunción de inocencia.

En el Capítulo IV, la Prof. Dra. Natalia Veloso Giribaldi pone de relieve los aspectos más salientes aplicación del principio de non bis in idem en el derecho administrativo sancionador.

En el Capítulo V, se aborda el principio de debido procedimiento. El Dr. Jose Pedro Montero estudia la aplicación de este principio desde un punto de vista práctico, analizando como se traduce dicho principio al procedimiento administrativo sancionador, a la luz de la jurisprudencia. Asimismo, la Dra. Stefanie Karina Antenor De León realiza un estudio del alcance del derecho de defensa y su tratamiento jurisprudencial. Finalmente, el Dr. Santiago Inchausti Pinto, analiza la aplicación de las medidas cautelares o provisionales en materia administrativo sancionatoria, con especial foco en la materia ambiental.

En el Capítulo VI, el Dr. German Mora Caruso examina los principios de obligatoriedad y oportunidad en el principio administrativo sancionador, analizando si el Estado puede o no decidir no perseguir y sancionar una infracción administrativa.

En el Capítulo VII, se aborda el principio de proporcionalidad en el derecho administrativo sancionatorio. El suscrito, Dr. Federico Fischer Castells, analiza la regulación y aplicación de los criterios de graduación de sanciones administrativas en el derecho administrativo sancionatorio nacional y las problemáticas que la falta de regulación uniforme plantea en la aplicación de este instituto. Por su parte, con un enfoque práctico, la Dra. Maite Dalmao Rodriguez ilustra acerca de la aplicación del principio de proporcionalidad en la jurisprudencia reciente del Tribunal de lo Contencioso Administrativo. Asimismo, la Esc. Verónica Morelli Ferreira y la Dra. Ana Muria, en sendos trabajos, estudian este principio como límite a la discrecionalidad de la administración en materia sancionatoria. Finalmente, el Dr. José Grassi Pampilega, estudia el principio de proporcionalidad en el nuevo marco legal del Banco Central de Paraguay.

Por último, en el Capítulo VII, la Dra. Adriana Allende aborda el principio de seguridad jurídica, estudiando los plazos de prescripción y caducidad del Derecho Administrativo Sancionador a la luz del principio de seguridad jurídica, exponiendo las diversas opiniones existentes al respecto en doctrina y jurisprudencia y la opinión de la autora.

Como comentario final, destaco que esta publicación no hubiera visto la luz de no ser por invaluable impulso y generosidad intelectual de la Prof. Dra. Veloso Giribaldi. Durante el curso de Derecho Administrativo Sancionador, la Prof. Dra. Veloso Giribaldi transmitió sus reflexiones sobre esta disciplina en forma didáctica y con un enfoque práctico, pero a la vez con gran profundidad y rigor jurídico, lo que despertó el interés en la materia y el impulso de investigar y reflexionar sobre sus principios generales de aquellos que participamos de dicho curso, y que fructificó en esta publicación.

En definitiva, vaya el reconocimiento a esta publicación, que sin duda contribuirá de manera significativa al estudio de los principios generales y la teoría del derecho administrativo sancionador. 